\title{
Inhalation exposure to particulate matter in a work environment of firefighters
}

\author{
Joanna Rakowska $^{1, *}$, Karolina Kuskowska ${ }^{1}$, Wioletta Rogula-Kozłowska ${ }^{2}$ \\ ${ }^{1}$ The Main School of Fire Service, Faculty of Civil Safety Engineering, 52/54 Slowackiego St., \\ 01-629 Warsaw, Poland \\ ${ }^{2}$ The Main School of Fire Service, Faculty of Fire Safety Engineering, 52/54 Slowackiego St., 01-629 \\ Warsaw, Poland
}

\begin{abstract}
The paper presents the results of research into the concentration of respirable and total particulate matter (PM) in a work environment of firefighters. Measurements were carried out from September 2017 to October 2017 during official capacity of firefighters, i.e. during firefighting, liquidation of other local hazards. The PM concentration was examined by the gravimetric method. For this purpose, two GilAir 3 aspirators and glass fibre filters were used. During the whole duty, the samplers were placed in the pockets of the uniform, while the measuring heads were harnessed to the collar of the uniform. The deposited mass of PM in the different regions of the respiratory tract was calculated using the Eulerian Multiple Path Particle Dosimetry model. Especially high PM concentrations were noted during firefighting, The PM deposits in the head, the trachea and bronchiolar and pulmonary alveolar regions were different depending on the action the firemen had to deal with.
\end{abstract}

\section{Introduction}

Firefighting is one of the most hazardous and until now the least studied occupations in terms of exposures to the hazardous agents and their relationship to occupational diseases. The International Organization of Research on Cancer (IARC) and the American National Institute for Occupational Health and Safety recognize occupational exposure in firefighting, mining, construction and agriculture as a possible mutagenic and carcinogen to humans [1-3]. Fires are important source of pollutant emission to the atmosphere, which translates into impact on the environment and human health, both on a local, regional or global scale. The most important air pollutants are particulate matter (PM), carbon dioxide $\left(\mathrm{CO}_{2}\right)$, carbon monoxide $(\mathrm{CO})$, including sulfur dioxide $\left(\mathrm{SO}_{2}\right)$, nitrogen oxides $\left(\mathrm{NO}_{\mathrm{x}}\right)$ and nitrous oxide $\left(\mathrm{N}_{2} \mathrm{O}\right)$, hydrogen cyanide $(\mathrm{HCN})$, phosphorus pentoxide $\left(\mathrm{P}_{2} \mathrm{O}_{5}\right)$, hydrogen chloride $(\mathrm{HCl})$, hydrogen fluoride $(\mathrm{HF})$, hydrogen bromide $(\mathrm{HBr})$, acrolein, formaldehyde, and organic contaminants including methane $\left(\mathrm{CH}_{4}\right)$, non-methane hydrocarbons (NMHC), polycyclic aromatic hydrocarbons (PAHs), dioxins and dibenzofuran [4-6].

Smoke pollution due to fires can potentially pose a significant public health risk for communities directly affected by fires, in particular for personnel involved in firefighting

\footnotetext{
* Corresponding author: jrakowska@sgsp.edu.pl
} 
activities. But existing state of knowledge on the potential influence of fire gases emission on health of firefighters is still unsatisfactory. The reason of this status is the difficulty in collecting data on the human exposure to smoke during firefighting operations. The impact of fires on air quality depends on meteorology, fire dynamic, the amount and chemical composition of fuel, and the atmosphere. For example, the concentration of PM10 during various fires can range from $340 \mu \mathrm{g} / \mathrm{m}^{3}$ to $6000 \mu \mathrm{g} / \mathrm{m}^{3}$ [6]. Firefighters participating in rescue and firefighting operations may experience or have direct, acute or chronic effects due to exposure to smoke. To assess the occupational exposure of firefighters caused by air pollution contained in smoke, it is necessary to conduct research in this area.

As was proved, inhalation of particulate matter during firefighting causes an inflammatory response within the respiratory system and allergic sensitization. In health consequence these local reaction initiates a systemic response associated with air pollution exposure. This inflammatory procedure can be results even a short time contact with harmful compounds and low intensity exposure. For young and healthy firefighters this consequences may have lower clinical significance but is very crucial for persons with chronic cardiopulmonary diseases [7]. A source of significantly height PM concentrations are among others wildland fires and uncontrolled open fires involving industrial or commercial grounds which will represent a clear risk to health firefighters exposured to the smoke [8]. In addition to the firefighters' exposure to harmful combustion products during firefighting activities [9], firefighters may be exposed to these substances also when they are at fire stations. Chemical pollutions from fires were transferred back to the fire station using fire vehicles and mainly by personal fire equipment, such as protective clothing, shoes, helmet and gloves [10]. Few studies on occupational exposure of firefighter to harmful compounds at fire stations were found. The aim of the study was to preliminary evaluate of inhalation exposure to PM in a work environment of Polish firefighters $[9,11]$.

\section{Materials and methods}

The sampling of respirable $\left(\mathrm{PM}_{4}\right)$ and total suspended particles (TSP) was carried out in two independent periods including three 24-h work shifts: 18/21/27 September 2017 (Period I) and 03/06/09 October 2017 (Period II). The samples of PM were collected by one firefighter only during the action i.e. firefighting and liquidation of other local hazards. The PM concentration was examined by the gravimetric method [12]. For this purpose, two GilAir 3 aspirators and glass fiber filters were used. During sampling period, the samplers were placed in the pockets of the uniform, while the measuring heads were harnessed to the collar of the uniform. Based on PM concentrations the average 8-h inhaled doses of particles in the different regions of the RT i.e. head air ways $(\mathrm{H})$, trachea and bronchiolar (TB) and pulmonary alveolar (P) were calculated for each period using the Eulerian Multiple Path Particle Dosimetry model (MPPD V2.11, ARA Inc.). The deposited mass of PM was calculated for one breathing cycle including only inspiration (without expiration). The values of MMAD and GSD were calculated according to standard ISO7708-2011 [13]. Due to the fact that firefighters are only adults, the deposition was calculated for the age group over 21 years using age-specific symmetric lung model. The following exposure scenario was considered: upright body orientation, and nasal breathing under conditions of normal physiological activity. Specific physiological parameters used in calculations are summarized in Table 1 [14]. 
Table 1. Physiological parameters implemented into MPPD model.

\begin{tabular}{|c|c|c|c|c|c|}
\hline Age & $\begin{array}{c}\text { Breathing } \\
\text { Frequency } \\
\text { BF } \\
\text { [breaths/min] }\end{array}$ & $\begin{array}{c}\text { Tidal } \\
\text { Volume } \\
\text { TV } \\
\text { [ml] }\end{array}$ & $\begin{array}{c}\text { Functional } \\
\text { Reserve } \\
\text { Capacity } \\
\text { FRC } \\
\text { [m] }\end{array}$ & $\begin{array}{c}\text { Upper } \\
\text { Respiratory } \\
\text { Tract Volume } \\
\text { URT } \\
\text { [ml] }\end{array}$ & $\begin{array}{c}\text { Inspiratory } \\
\text { Fraction } \\
\text { IF }\end{array}$ \\
\hline $\begin{array}{c}\mathbf{2 1} \\
\text { years }\end{array}$ & 14 & 477.2 & 2792.5 & 42.3 & 0.5 \\
\hline
\end{tabular}

\section{Results and discussion}

In Table 2 the average 24-h concentrations of PM sampled during firefighting and rescue operations for two periods (18/21/27 September 2017 and 03/06/09 October 2017) are presented. In general, the concentrations of PM during rescue and extinguishing operations are high. It should be noted, that in this paper the concentrations of PM collected only during the operation is analyzed. According to The Register of Accidents of the FireRescue Unit, participations in actions constitutes $30 \%$ of the 24 -hour fireman's duty. Due to the fact that each measurement period comprised 3 duties, the presented concentrations concern a total of 24-hour measurement period. By comparing the obtained results with other studies of concentrations of PM in the workplace, it follows that the 24-h concentration of the fine fraction during rescue and fire extinguishing operations were almost two times higher than a 8-h concentration of this faction during the grinding in the production plant. The concentrations of total suspended particles were comparable [15]. According to the "Register of Firefighter Activities" created by a fireman who carrying measuring devices, during the first measurement period PM samples were collected during the following actions: liquidation of the effects of road accidents, neutralization of chemical leakage, fires of arbor, flats and residential buildings. In the second period the samples of PM were collected during following actions: a large-area fire of a warehouse, accident of a public transport bus, fire of farm buildings, fire of flats and, as in the case of the first period - liquidation of the effects of road accidents. Comparing the activities carried out in the first and second measurement period, it should be noticed that in the second period activities related to extinguishing fires were prevalent. It could be the reason for the higher concentrations of both the respirable fraction PM4 and total suspended particles TSP recorded in this period. Particularly high concentrations were noted for the $\mathrm{PM}_{4}$. Its mass during the first measurement period constituted approximately $60 \%$ of the mass of TSP in $1 \mathrm{~m}^{3}$ of air, while during the second period as much as $86 \%$ (Table 2).

Table 2. Concentrations of particulate matter collected during firefighting and liquidation of other local hazards in two measurement periods.

\begin{tabular}{|c|c|c|}
\hline \multirow[t]{2}{*}{ Measurement period } & \multicolumn{2}{|c|}{$\begin{array}{c}\mathrm{PM} \\
\text { concentration } \\
{\left[\mu \mathrm{g} / \mathrm{m}^{3}\right]}\end{array}$} \\
\hline & $\mathrm{PM}_{4}$ & TSP \\
\hline 18/21/27 September 2017 & 42 & 70 \\
\hline 03/06/09 October 2017 & 86 & 100 \\
\hline
\end{tabular}

The high values of PM deposition in various sections of the respiratory tract are other factor resulting from the conducted research, which identicates the problem of air pollination at the firefighter's work (Fig. 1). As it results from the simulation, in the first measurement period about $80 \%$ of the PM mass suspended in $1 \mathrm{~m}^{3}$ of ambient air is 
deposited in the airways, while in the second period it is about $90 \%$. High health exposure of firefighters who participate in rescue and firefighting operations results from the fact that both in the first and in the second measurement period the size of deposition in the alveoli is 23 and $29 \%$ respectively. These values mean that about $1 / 4$ of the PM inhaled by firefighters reaches the deepest regions of the respiratory system. Differences in the deposition rates in the considered measurement periods result from differences in PM concentrations and the mass distribution of the PM relative to the particle aerodynamic diameter. As it results from the measurements and observations, this distribution depends on the type of accidents which eliminate firefighters and precisely on the number of fires, because probably the fires determine the highest concentrations at firefighter workplace. It should be noted that in comparison to other studies of deposition values at workplaces, the calculated PM masses deposited in the airways during the rescue and firefighting operations are higher than the depositions designated for people living in urbanized and industrial areas of southern Poland, i.e. in Zabrze $\left(47.4 \mu \mathrm{g} / \mathrm{m}^{3}\right.$ - winter season, $25.3 \mu \mathrm{g} / \mathrm{m}^{3}$ - summer season) [16] as well as citizens of center of Beijing (approx. $20 \mu \mathrm{g} / \mathrm{m}^{3}$ ) [17] or Shanghai (approx. $80 \mu \mathrm{g} / \mathrm{m}^{3}$ ) [18].

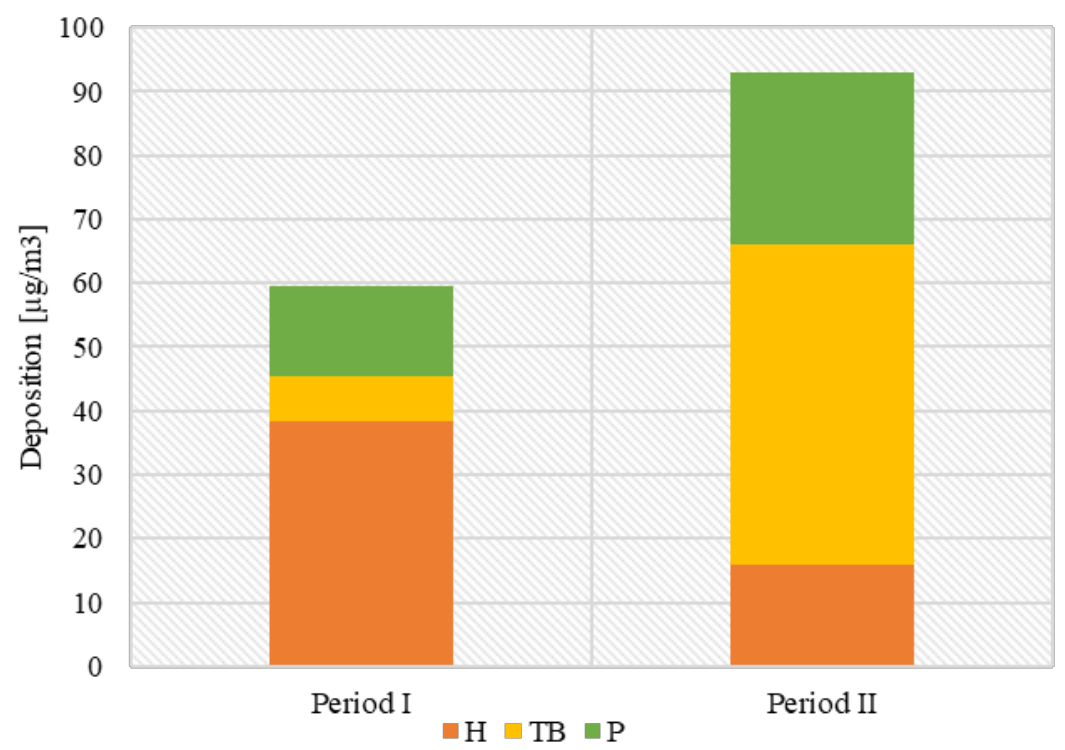

Fig. 1. Relative deposited PM mass in different regions of respiratory tract: head airways $(H)$ trachea and bronchi (TB) and pulmonary regions (P) for firefighters during rescue and firefighting operations.

\section{Conclusions}

Studies described in this paper indicates that inhalation exposure to particulate matter in a work environment of firefighters is high (approx. $60 \mu \mathrm{g} / \mathrm{m}^{3}$ - period I, approx. $92 \mu \mathrm{g} / \mathrm{m}^{3}$ period II). This exposure results from high concentrations of the fine fraction whose main source during the research was fires. Diversity of actions conducted by firefighters during duty caused that deposition coefficients in different compartments of respiratory tract are different during each duty. Results of studies suggest that firefighters should use personal protection equipment such as face masks during the operation. This solution would reduce the amount of inhaled PM particles. 


\section{References}

1. IARC Monographs on the Evaluation of Carcinogenic Risks to Humans. Painting, firefighting and shiftwork (Lyon, France, 2010).

2. NIOSH Pocket Guide to Chemical Hazards (U.S. Department of Health and Human Services, Public Health Service, Centers for Disease Control and Prevention, Cincinnati, USA, 2007).

3. J. Swiston, W. Davidson, S. Attridge, G. Li, M. Brauer, S. van Eeden, ERJ 32, 129 (2008)

4. A. Miranda , V. Martins, P. Cascão, J. Amorim, J. Valente, R. Tavares, C. Borrego, O. Ferreira, C. Cordeiro, D. Viegas, L. Ribeiro, L. Pita, Env. Int. 36, 736 (2010)

5. S. Urbanski, W. Hao, S. Baker, Develop. Environ. Sci. 8, 79 (Elsevier, 2009)

6. S. Griffiths, P. Chappell, J. Entwistle, F. Kelly, M. Deary, Env. Int. 112, 310 (2018).

7. N. Gianniou, P. Katsaounou, E. Dima, C. Giannakopoulou, M. Kardara, V. Saltagianni, R. Trigidou, A. Kokkini, P. Bakakos, E. Markozan, E. Litsiou, A. Tsakatikas, C. Papadopoulos, C. Roussos, N. Koulouris, N. Rovina, Respir. Med. 118, 7 (2016)

8. A. Stec, FSJ 91, 79 (2017)

9. C. Baxter, J. Hoffman, M. Knipp, T. Reponen, E. Haynes, J. Occup. Environ. Hyg. 11, D85 (2014)

10. B. Alexander, C. Baxter, J. Occup. Environ. Hyg. 11, D43 (2014).

11. M. Oliveira, K. Slezakova, M. Alves, A. Fernande, J. Teixeirad, C. Delerue-Matosa, M. do Carmo Pereirab, S. Moraisa, J. Haz. Mat. 323, 184 (2017)

12. W. Rogula-Kozłowska, Air Quality Atmos. Health 9, 533 (2016)

13. ISO $7708: 2001$

14. G. Bezemer, Particle Deposition Clearance from Respiratory Tract (University of Utrecht, Netherlands: Institute for Risk Assessment Sciences, 2009)

15. D. Kondej, E. Jankowska, Bezpieczeństwo pracy 10, 16 (2004)

16. A. Zwoździak, M. Gini, L. Samek, W. Rogula-Kozłowska, I. Sówka, J. Aerosol Sci. 103, 38 (2017)

17. X. Li, C. Yan, R. Patterson, Y. Zhu, X. Yao, Atmos. Environ. 124, 387 (2016)

18. G. Guo, B. Song, D. Xia, Z. Yang, F. Wang, Environ. Geochem. Health. doi.org/10.1007/s10653-018-0083-2 (2018) 